\title{
The incidence of hip, forearm, humeral, ankle, and vertebral fragility fractures in Italy: results from a 3-year multicenter study
}

\author{
Umberto Tarantino ${ }^{1 *}$, Antonio Capone ${ }^{2}$, Marco Planta ${ }^{2}$, Michele D'Arienzo $^{3}$, Giulia Letizia Mauro ${ }^{4}$, \\ Angelo Impagliazzo ${ }^{5}$, Alessandro Formica ${ }^{5}$, Francesco Pallotta ${ }^{6}$, Vittorio Patella ${ }^{7}$, Antonio Spinarelli ${ }^{7}$, Ugo Pazzaglia $^{8}$, \\ Guido Zarattini ${ }^{8}$, Mauro Roselli ${ }^{9}$, Giuseppina Montanari ${ }^{9}$, Giuseppe Sessa ${ }^{10}$, Marco Privitera ${ }^{10}$, Cesare Verdoia ${ }^{11}$, \\ Costantino Corradini ${ }^{11}$, Maurizio Feola ${ }^{1}$, Antonio Padolino ${ }^{1}$, Luca Saturnino ${ }^{1}$, Alessandro Scialdoni ${ }^{1}$, Cecilia Rao ${ }^{1}$, \\ Giovanni Iolascon ${ }^{12}$, Maria Luisa Brandi ${ }^{13}$, Prisco Piscitelli ${ }^{13}$
}

\begin{abstract}
Introduction: We aimed to assess the incidence and hospitalization rate of hip and "minor" fragility fractures in the Italian population.

Methods: We carried out a 3-year survey at 10 major Italian emergency departments to evaluate the hospitalization rate of hip, forearm, humeral, ankle, and vertebral fragility fractures in people 45 years or older between 2004 and 2006, both men and women. These data were compared with those recorded in the national hospitalizations database (SDO) to assess the overall incidence of fragility fractures occurring at hip and other sites, including also those events not resulting in hospital admissions.

Results: We observed 29,017 fractures across 3 years, with hospitalization rates of 93.0\% for hip fractures, 36.3\% for humeral fractures, $31.3 \%$ for ankle fractures, $22.6 \%$ for forearm/wrist fractures, and $27.6 \%$ for clinical vertebral fractures. According to the analyses performed with the Italian hospitalization database in year 2006, we estimated an annual incidence of 87,000 hip, 48,000 humeral, 36,000 ankle, 85,000 wrist, and 155,000 vertebral fragility fractures in people aged 45 years or older (thus resulting in almost 410,000 new fractures per year). Clinical vertebral fractures were recorded in 47,000 events per year.
\end{abstract}

Conclusions: The burden of fragility fractures in the Italian population is very high and calls for effective preventive strategies.

\section{Introduction}

Italy has one of the highest life expectancies in the world: according to the Italian National Institute for Statistics (ISTAT), life expectancy at birth increased at a rate of 4 months per year from 1950 to 2005, reaching 78.4 years for men and 87.4 years for women, respectively $[1,2]$. Twenty percent of the Italian population $(12,085,058$ people) is actually older than 65 years [1], but $5.6 \%$ of these are 80 years and older [1]. The

\footnotetext{
* Correspondence: umberto.tarantino@uniroma2.it

'Division of Orthopaedics and Traumatology, Tor Vergata Foundation University Hospital, University of Rome, Tor Vergata, Viale Oxford 81, Rome, 00133, Italy

Full list of author information is available at the end of the article
}

national aging index was recently computed at 143.1, with southern Italian regions younger than northern areas of the country [1]. Increased life expectancy is associated with a greater frailty of elderly people and a higher prevalence of chronic and degenerative diseases, including osteoporosis. The World Health Organization (WHO) considers osteoporosis to be second only to cardiovascular diseases as a critical health problem [3], and previous analyses have shown that the incidence and costs of hip fractures in Italy are already comparable to those of acute myocardial infarction [4]. The main Epidemiological Study on the Prevalence of Osteoporosis in Italy (ESOPO) reported a high prevalence of osteoporosis: $23 \%$ among all women, with age-specific rates 
ranging from $9 \%$ (40- to 49 -year-olds) up to $45 \%$ (70 to 79 years or older), and almost $15 \%$ in men aged 60 years and older [5,6]. According to these data, about 4 million of Italian women and 800 thousand men are thought to be affected by osteoporosis [2]. However, an overestimation of these prevalence data cannot be excluded, as the ESOPO study was conducted by using QUS (quantitative ultrasound) measurements, given the lack of national epidemiologic studies performed by using DEXA (dual-energy $x$-ray absorptiometry), the gold-standard tool in the diagnosis of osteoporosis [6-8]. It is known that osteoporosis is a condition that enhances the risk of fractures [9], and osteoporotic fractures represent a challenge for health professionals and decision makers in the $21^{\text {st }}$ century. Despite these observations, only limited data are available about the incidence of fragility fractures in the Italian population [10-13], particularly concerning fractures occurred in skeletal sites other than hip. Vertebral fractures or deformities are the most common osteoporotic fractures [14]. According to the European Vertebral Osteoporosis Study (EVOS), in about $12 \%$ of both men and women aged 50 through 80 years, it is possible to detect vertebral deformities, with their prevalence increasing with age in both sexes [15]. Vertebral deformities, even if asymptomatic, are associated with adverse outcomes, including back pain, physical impairment $[16,17]$, a higher risk of subsequent osteoporotic fractures [18-20], and an increased risk of mortality $[19,21]$. However, two thirds of vertebral fractures do not come to clinical attention [22], and it is very difficult to assess their incidence among the general population. Wrist or forearm fractures represent the most common breakage among perimenopausal women (typically between 40 and 50 years old), with their incidence increasing quickly after the menopause, probably as a consequence of a hormonerelated fast bone-loss process, but reaching a plateau after the age of 65 [23]. Wrist fractures are also frequent in men younger than 70 years, but the age-adjusted female-to-male ratio remains 4:1 [23]. Wrist fractures increase almost twofold the risk of subsequent hip or vertebral fractures, but also the risk of new forearm breakage and other skeletal fractures is increased by 3.3 and 2.4 times, respectively [24]. Humeral fractures represent the third most common fracture in people aged 65 years and older and have been associated with a higher risk of subsequent hip fractures [25]. Actually, a proximal humeral fracture increases more than 5 times the risk of hip fracture at 1 year [25]. Incidence rates estimated for fractures of the proximal humerus and other skeletal sites increase with age and seem to be more frequent in women with poor neuromuscular function but also in aging men, with $75 \%$ of these fractures being caused by moderate- or low-energy trauma
$[23,26]$. Even fractures occurring at foot/ankle or ribs have been found to double the risk of subsequent hip, vertebral, forearm, or other skeletal fractures [24], thus confirming that all osteoporotic fractures should be considered the first signal of an evolving disease. Our aim was to estimate the incidence and hospitalization rate of the most common fragility fractures in Italy: hip fractures, and, for the first time, other "minor" fractures such as forearm, humeral, ankle, and vertebral fractures, which do not result automatically in hospital admissions.

\section{Materials and methods \\ Patients and survey}

We carried out a survey of 29,017 fractured patients referring to the emergency departments of 10 major Italian hospitals in different Northern, Central, and Southern regions of the country. The hospitals involved in the survey were the following: Milan (Othopedic Institute "Gaetano Pini"), Turin (Maria Vittoria Hospital), Brescia (Riuniti Hospital), Rome (Tor Vergata University Hospital, St. Camillo Hospital and St. Giovanni Addolarata Hospital), Cagliari (University Hospital), Palermo (University Hospital), Bari (University Hospital), and Catania (University hospital). Orthopedic surgeons at each hospital were involved in this survey, because all kinds of fractures admitted to emergency departments were treated by orthopaedics departments. Physicians involved were asked systematically to record specific data concerning the fractures observed between 01/01/2004 and $31 / 12 / 2006$ : the skeletal site of the fracture, the gender and age of the patient, and the type of trauma of the patient (low-energy trauma or not). Fractures incurred because of low-energy trauma were considered osteoporotic fragility fractures. Orthopedic surgeons involved in the study recorded whether the patient was discharged from emergency department after having been treated or if the patient was hospitalized because of the fracture. The survey included hip, humeral, ankle, forearm, and vertebral fractures. Information obtained did not include demographic factors, osteoporotic status, tobacco and alcohol history, medications consumption, history of falls, fracture risk factors, or previous fracture history. The patient age was computed from date of birth. Participants were stratified into three age groups: 45 to 64,65 to 74 , and 75 years or older. Because the osteoporotic status of the participants was not instrumentally investigated (no data concerning bone mineral density were available) and to be more conservative, avoiding false-positive cases, men aged 45 to 64 years $(n=$ 3,183 ) were always excluded from data analyses, even though their fractures were classified as due to low-energy trauma. Conversely, women in the same age group (45 to 64 years old; $n=5,501$ ) were included only in the data 
analyses concerning humeral, ankle, wrist, and vertebral fractures (but not in the analysis of hip fragility fractures, which were computed only in those older than 65 years) because of the high prevalence of these kinds of "minor" fragility fractures in younger postmenopausal women $[15,23]$. For each kind of fracture, we computed the number of patients requiring hospital admission and the number of patients discharged directly from the emergency department after having been examined and treated (radiologic examination, orthopedic evaluation, and treatments not requiring hospitalization). The hospitalization rate (the percentage of patients requiring hospital admission versus the overall number of patients with a hip, wrist, humeral, ankle, or vertebral fracture) was computed for each kind of fracture. Population data concerning the 3 examined years were obtained from the Italian Institute for Statistics (ISTAT). Data were processed by using Stata (StataCorp, College Station, TX, USA) and Excel (Microsoft, Redmond, WA, USA) software.

\section{Comparative analysis}

The second part of our study consisted of the analysis of the National Hospital Discharge records (SDO) maintained at the Italian Ministry of Health, concerning the 3 years of our survey (2004 through 2006). In this archive, information concerning all hospitalizations occurring in Italian public and private care settings are collected. These data are anonymous and include the patient's age, diagnosis, procedures performed, and length of the hospitalization. It is known that about $90 \%$ of hip fractures systematically result in hospitalization, thus allowing researchers to perform epidemiologic analyses by using hospital discharge records [13]. Conversely, only a small proportion of patients with osteoporotic fractures at other different skeletal sites are hospitalized [23], so that hospital discharge records cannot simply be used to investigate the prevalence of most osteoporotic fractures. In this perspective, we have used the hospitalization rates observed in the sample of our multicenter survey for each kind of fracture (humeral, ankle, forearm, hip, and vertebral fractures) to estimate the number of fracture patients discharged all over the country from emergency departments without being hospitalized. Descriptive statistical analyses were used to calculate the annual incidence of hip, humeral, ankle, forearm, hip, and vertebral fractures in the whole Italian population, by applying the hospitalization rates observed in our survey to the number of hospital admissions available at the national level for each kind of fracture across the 3 examined years. Because almost all patients with hip, humeral, ankle, or forearm fractures are referred to the hospital, whereas only a minority (from $22 \%$ to $33 \%$ ) of vertebral fractures, defined as "clinical vertebral fractures," come to medical attention
[27-30], we had to perform a corrective analysis to estimate the incidence rate of vertebral fractures in the whole Italian population. The hospitalization rate computed in our survey concerning vertebral fractures included only patients referring to the hospital because of clinical vertebral fractures, whereas the majority of vertebral deformities (from $78 \%$ to $67 \%$ ) are asymptomatic and do not require admission at emergency departments [27-30]. To be conservative, we considered $70 \%$ of vertebral deformities occurring in Italy to be asymptomatic, and $30 \%$ of them as "clinical" fractures. Therefore, we took into account this proportion when performing comparative analyses between the hospitalization rate computed for vertebral fractures in our survey and data from the National Hospitalization Database (SDO). To acquire all the necessary data concerning hospitalizations, the SDO archive was enquired for the following ICD-9CM diagnosis codes (limited to major diagnosis): 820.0 to 820.1 (femoral neck fractures), 820.2 to 820.3 (per-trochanteric femoral fractures), 820.8 , $820.9,821.1$ (other femoral fractures), 812 (humeral fractures), 824 (ankle fractures), 813 (forearm/wrist fractures), and 805 (vertebral fractures). Data were stratified by gender and into three age groups ( 65 to 74 years and 75 years and older) and were processed by using Stata (StataCorp) and Excel (Microsoft) software.

\section{Results}

An overall number of 29,017 patients with fractures were enrolled over a period of 3 years. Table 1 shows the composition of the population involved in the survey per each selected age group and the distribution per age group and gender of the enrolled patients, both those discharged from Emergency Department and those hospitalized after any fracture considered in the protocol. Tables 2, 3, 4, 5, and 6 show the yearly number of hospitalizations after hip, humeral, forearm/wrist, ankle, and vertebral fractures recorded during the study period in the Italian National Hospital Discharge records (SDO 2004-2005-2006). About 70\% of the overall fractures observed during the study period $(n=20,333)$ occurred in persons aged older than 65 years. In total, 25,495 were classified by clinicians as fragility fractures (a consequence of low-energy trauma), whereas 3,522 events were regarded as fractures induced by high-energy trauma, mostly affecting men aged 45 through 64 years old $(n=3,183)$. We recorded a total of 8,290 hip fragility fractures (1,974 men and 6,316 women), 4,559 humeral fragility fractures (976 men and 3,583 women), 2,981 ankle fragility fractures (494 men and 2,487 women), 6,514 forearm/wrist fragility fractures (786 men and 5,728 women), and 2,927 vertebral fragility fractures (577 men and 2,350 women). Hospitalization rates were the following: $93.0 \%$ for hip fractures $(n=7,711), 36.3 \%$ 
Table 1 Study sample: enrolled patients distributed per age group, gender, and hospitalization status

\begin{tabular}{|c|c|c|c|c|c|c|c|}
\hline \multicolumn{2}{|c|}{ Age group (years) } & \multicolumn{2}{|c|}{ Males } & \multicolumn{2}{|c|}{ Females } & \multicolumn{2}{|c|}{ Total $(M+F)$} \\
\hline & & ER Not hospitalized & Hospitalized & ER Not hospitalized & Hospitalized & ER Not hospitalized & Hospitalized \\
\hline \multirow{2}{*}{\multicolumn{2}{|c|}{45 to 64}} & 1,812 & 1,371 & 3,575 & 1,926 & 5,387 & 3,297 \\
\hline & & 3,183 & & 5,501 & & 8,684 & \\
\hline \multirow{2}{*}{\multicolumn{2}{|c|}{65 to 74}} & 988 & 901 & 2,911 & 2,138 & 3,899 & 3,039 \\
\hline & & 1,889 & & 5,049 & & 6,938 & \\
\hline \multirow{2}{*}{\multicolumn{2}{|c|}{ Older than 75}} & 1,047 & 1,871 & 4,235 & 6,242 & 5,282 & 8,113 \\
\hline & & 2,918 & & 10,477 & & 13,395 & \\
\hline \multirow[t]{2}{*}{ Total } & $E R / H$ & 3,847 & 4,143 & 10,721 & 10,306 & 14,568 & 14,449 \\
\hline & $E R+H$ & 7,990 & & 21,027 & & 29,017 & \\
\hline
\end{tabular}

ER, patients referring to Emergency Room.

Table 2 Yearly number of hospitalizations after hip fractures recorded in the National Hospital Discharge records (SDO, 2004, 2005, 2006) maintained at the Italian Ministry of Health

\begin{tabular}{llllllllll}
\hline & \multicolumn{9}{c}{$\mathbf{2 0 0 4}$} \\
\cline { 2 - 10 } Age (years) & $\mathbf{M}$ & $\mathbf{F}$ & Subtotal & $\mathbf{M}$ & $\mathbf{F}$ & Subtotal & $\mathbf{M}$ & $\mathbf{F}$ & Subtotal \\
\hline 45 to 64 & 2,979 & 3,810 & 6,789 & 2,961 & 3,632 & 6,593 & 3,002 & 3,804 & 6,806 \\
65 to 74 & 3,813 & 9,430 & 13,243 & 3,660 & 9,352 & 13,012 & 3,765 & 9,322 & 13,087 \\
Older than 75 & 12,958 & 49,589 & 62,547 & 13,937 & 52,051 & 65,988 & 14,593 & 53,259 & 67,852 \\
Total & 19,750 & 62,829 & 82,579 & 20,558 & 65,035 & 85,593 & 21,360 & 66,385 & 87,745 \\
\hline
\end{tabular}

These data exclude hospital readmissions of the same patients.

Table 3 Yearly number of hospitalizations after humeral fractures recorded in the National Hospital Discharge records (SDO, 2004-2005-2006) maintained at the Italian Ministry of Health

\begin{tabular}{|c|c|c|c|c|c|c|c|c|c|}
\hline \multirow[b]{2}{*}{ Age (years) } & \multicolumn{3}{|c|}{2004} & \multicolumn{3}{|c|}{2005} & \multicolumn{3}{|c|}{2006} \\
\hline & $\bar{M}$ & $F$ & Subtotal & $M$ & $F$ & Subtotal & $M$ & $F$ & Subtota \\
\hline 45 to 64 & 1,994 & 3,159 & 5,153 & 2,005 & 3,323 & 5,328 & 2,123 & 3,355 & 5,478 \\
\hline 65 to 74 & 1,026 & 4,247 & 5,273 & 1,099 & 4,240 & 5,339 & 1,138 & 4,311 & 5,449 \\
\hline Older than 75 & 1,370 & 6,949 & 8,319 & 1,437 & 7,077 & 8,514 & 1,425 & 7,452 & 8,877 \\
\hline Total & 4,390 & 14,355 & 18,745 & 4,541 & 14,640 & 19,181 & 4,686 & 15,118 & 19,804 \\
\hline
\end{tabular}

These data exclude hospital readmissions of the same patients.

Table 4 Yearly number of hospitalizations after forearm/wrist fractures recorded in the National Hospital Discharge records (SDO, 2004-2005-2006) maintained at the Italian Ministry of Health

\begin{tabular}{|c|c|c|c|c|c|c|c|c|c|}
\hline \multirow[t]{2}{*}{ Age (years) } & \multicolumn{3}{|c|}{2004} & \multicolumn{3}{|c|}{2005} & \multicolumn{3}{|c|}{2006} \\
\hline & $\mathrm{M}$ & $\mathrm{F}$ & Subtotal & $M$ & $F$ & Subtotal & $M$ & $F$ & Subtotal \\
\hline 45 to 64 & 3,808 & 6,270 & 10,078 & 3,886 & 6,308 & 10,194 & 4,029 & 6,610 & 10,639 \\
\hline 65 to 74 & 1,227 & 5,125 & 6,352 & 1,241 & 5,160 & 6,401 & 1,209 & 5,036 & 6,245 \\
\hline Older than 75 & 826 & 5,322 & 6,148 & 875 & 5,461 & 6,336 & 872 & 5,550 & 6,422 \\
\hline Total & 5,861 & 16,717 & 22,578 & 6,002 & 16,929 & 22,931 & 6,110 & 17,196 & 23,306 \\
\hline
\end{tabular}

These data exclude hospital readmissions of the same patients.

Table 5 Yearly number of hospitalizations after ankle fractures recorded in the National Hospital Discharge records (SDO, 2004-2005-2006) maintained at the Italian Ministry of Health

\begin{tabular}{|c|c|c|c|c|c|c|c|c|c|}
\hline \multirow[b]{2}{*}{ Age (years) } & \multicolumn{3}{|c|}{2004} & \multicolumn{3}{|c|}{2005} & \multicolumn{3}{|c|}{2006} \\
\hline & $M$ & $F$ & Subtotal & $M$ & $F$ & Subtotal & $M$ & $F$ & SUBTOTAL \\
\hline 45 to 64 & 3,177 & 5,106 & 8,283 & 3,125 & 5,025 & 8,150 & 3,344 & 4,919 & 8,263 \\
\hline 65 to 74 & 1,187 & 2,778 & 3,965 & 1,213 & 2,732 & 3,945 & 1,236 & 2,839 & 4,075 \\
\hline Older than 75 & 633 & 1,728 & 2,361 & 681 & 1,777 & 2,458 & 721 & 1,765 & 2,486 \\
\hline Total & 4,997 & 9,612 & 14,609 & 5,019 & 9,534 & 14,553 & 5,301 & 9,523 & 14,824 \\
\hline
\end{tabular}


Table 6 Yearly number of hospitalizations after vertebral fractures recorded in the National Hospital Discharge records (SDO, 2004-2005-2006) maintained at the Italian Ministry of Health

\begin{tabular}{|c|c|c|c|c|c|c|c|c|c|}
\hline \multirow[b]{2}{*}{ Age (years) } & \multicolumn{3}{|c|}{2004} & \multicolumn{3}{|c|}{2005} & \multicolumn{3}{|c|}{2006} \\
\hline & $M$ & $\mathrm{~F}$ & Subtotal & $M$ & $F$ & Subtotal & $M$ & $\mathrm{~F}$ & Subtotal \\
\hline 45 to 64 & 3,079 & 2,678 & 5,757 & 2,998 & 2,614 & 5,612 & 3,021 & 2,667 & 5,688 \\
\hline 65 to 74 & 1,735 & 2,560 & 4,295 & 1,821 & 2,557 & 4,378 & 1,891 & 2,583 & 4,474 \\
\hline Older than 75 & 1,644 & 3,812 & 5,456 & 1,697 & 3,841 & 5,538 & 1,832 & 3,942 & 5,774 \\
\hline Total & 6,458 & 9,050 & 15,508 & 6,516 & 9,012 & 15,528 & 6,744 & 9,192 & 15,936 \\
\hline
\end{tabular}

These data exclude hospital readmissions of the same patients.

for humeral fractures $(n=1,657), 31.3 \%$ for ankle fractures $(n=932), 22.6 \%$ for forearm/wrist fractures $(n=$ $1,475)$, and $27.6 \%$ for clinical vertebral fractures $(n=$ 809). Conversely, emergency departments directly discharged $7.0 \%$ of hip fracture patients $(n=579), 63.7 \%$ of humeral fractures $(n=2,902), 68.7 \%$ of ankle fractures $(n=2,049), 77.4 \%$ of forearm/wrist fractures $(n=$ $5,039)$, and $72.4 \%$ of vertebral fractures $(n=2,118)$. Women accounted for $49.0 \%$ of the overall hospitalizations and for $51.0 \%$ of total discharges from the emergency departments. Tables 7, 8, 9, 10, and 11 list the number of patients hospitalized or discharged from the emergency department after hip, humeral, ankle, forearm/wrist, and vertebral fractures per gender and age group. According to the analyses performed on the National Hospitalizations Database, the overall number of hip and other "minor" fragility fractures occurring each year in Italy has been estimated at almost 410,000 events. The annual incidence of the overall most common fragility fractures (hip, wrist, vertebral, humeral, and ankle fractures) per 100 inhabitants has been estimated up to 1.53 in men aged older than 65 years and up to 3.94 in women of the same age group. The incidence per 100 inhabitants reached 2.35 and 4.67 in men and women aged older than 75 years, respectively (with women aged older than 75 years the age group in which the highest number of fragility fractures was detected). Table 12 summarizes the incidence of fragility fractures per 100 inhabitants in year 2006 (according to gender and overall). Specifically, we estimated for the year 2006 (Table 13) an annual incidence of about 87,000 hip fragility fractures (corresponding to an incidence rate of 0.75 per 100 people older than 65 years: 0.41 for men and up to 1.0 for women), 48,000 humeral fragility fractures $(0.16$ for men older than 64 years and 0.28 for women older than 45 years), 36,000 ankle fragility fractures $(0.19$ per 100 adults aged $>45: 0.11$ for men and 0.22 for women), 85,000 forearm/wrist fragility fractures (0.44 per 100 adults older than 45 years: 0.15 for men and up to 0.55 for women), and 155,000 vertebral fractures (0.24 per 100 adults older than 45 years: 0.22 for men and up to 0.25 for women). Clinical vertebral fractures were estimated at 47,000 events per year ( 0.24 per 100 adults 45 years and older: 0.22 for men and up to 0.25 for women), and were assumed to represent almost $30 \%$ of the overall incident vertebral fractures [22,27-30]. The ratio of female-to-male patients (F/M ratio) for each kind of fracture always showed positive values in favor of women, with an increasing trend from the youngest to the oldest age group (Table 13). The highest F/M ratio (9.04) was observed for wrist fractures in people aged 65 years and older (5.09 in people aged 65 to 74 years and 9.04 in those older than 75 years). Humeral fractures showed an F/M ratio of 4.10 for people older than 65 years (2.99 in people aged 65 through 74 years old, and 4.98 for those older than 75 years). The F/M ratio for hip fractures was 3.43 for people older than 65 (2.48 in people aged T F/M ratio for all vertebral fractures was 2.64 over 65 of age, 2.01 in people aged between 65 and 74 years, and 3.27 in subjects older than 75 years.

\section{Discussion}

Hip fractures in Italy represent a serious health problem, and our estimations are consistent with other figures reported in previous national studies [4,13], which have estimated an increasing trend in the number of hospitalizations after hip fractures in Italy up to 94,000 admissions in the year 2005 (corresponding to about 85,000 individual patients). Conversely, fragility fractures

Table 7 Hip fragility fractures

\begin{tabular}{lllclll}
\hline $\mathbf{M}$ & $\mathbf{F}$ & Subtotal patients hospitalized & Age group (years) & $\mathbf{M}$ & $\mathbf{F}$ & Subtotal patients not hospitalized \\
\hline 412 & 951 & 1,363 & $\mathbf{6 5}$ to $\mathbf{7 4}$ & 37 & 88 & 125 \\
1,433 & 4,915 & 6,348 & Older than $\mathbf{7 5}$ & 92 & 362 & 454 \\
1,845 & 5,866 & 7,711 & Total & 129 & 450 & 579 \\
\hline Patients hospitalized & $93.0 \%$ & & Patients not hospitalized & $7.0 \%$ \\
\hline
\end{tabular}

Number of patients hospitalized because of the fracture versus number of patients discharged directly from the Emergency Department. 
Table 8 Humeral fragility fractures

\begin{tabular}{lllclll}
\hline $\mathbf{M}$ & $\mathbf{F}$ & Subtotal patients hospitalized & Age group (years) & $\mathbf{M}$ & $\mathbf{F}$ & Subtotal patients not hospitalized \\
\hline $\mathbf{1 3 6}$ & 332 & 332 & $\mathbf{4 5}$ to $\mathbf{6 4}$ & & 473 & 473 \\
179 & 405 & 541 & $\mathbf{6 5}$ to $\mathbf{7 4}$ & 284 & 581 & 865 \\
315 & 605 & 784 & Older than $\mathbf{7 5}$ & 377 & 1,187 & 1,564 \\
\hline \multicolumn{2}{l}{ Patients hospitalized } & $36.3 \%$ & Total & 661 & 2,241 & 2,902 \\
\hline
\end{tabular}

Number of patients hospitalized because of the fracture versus number of patients discharged directly from the Emergency Department.

Table 9 Ankle fragility fractures

\begin{tabular}{|c|c|c|c|c|c|c|}
\hline$M$ & $\mathbf{F}$ & Subtotal patients hospitalized & Age group (years) & M & $\mathbf{F}$ & Subtotal patients not hospitalized \\
\hline & 377 & 377 & 45 to 64 & & 657 & 657 \\
\hline 119 & 212 & 331 & 65 to 74 & 185 & 531 & 716 \\
\hline 58 & 166 & 224 & Older than 75 & 132 & 544 & 676 \\
\hline 177 & 755 & 932 & Total & 317 & 1,732 & 2,049 \\
\hline \multicolumn{2}{|c|}{ Patients hospitalized } & $31.3 \%$ & & \multicolumn{2}{|c|}{ Patients not hospitalized } & $68.7 \%$ \\
\hline
\end{tabular}

Number of patients hospitalized because of the fracture versus number of patients discharged directly from the Emergency Department.

Table 10 Forearm fragility fractures

\begin{tabular}{|c|c|c|c|c|c|c|}
\hline$M$ & $\mathbf{F}$ & Subtotal patients hospitalized & Age group (years) & M & $\mathbf{F}$ & Subtotal patients not hospitalized \\
\hline & 478 & 478 & 45 to 64 & & 1,814 & 1,814 \\
\hline 139 & 415 & 554 & 65 to 74 & 311 & 1,228 & 1,539 \\
\hline 93 & 350 & 443 & Older than 75 & 243 & 1,443 & 1,686 \\
\hline 232 & 1,243 & 1,475 & Total & 554 & 4,485 & 5,039 \\
\hline \multicolumn{2}{|c|}{ Patients hospitalized } & $22.6 \%$ & & \multicolumn{2}{|c|}{ Patients not hospitalized } & $77.4 \%$ \\
\hline
\end{tabular}

Number of patients hospitalized because of the fracture versus number of patients discharged directly from the Emergency Department.

Table 11 Vertebral fragility fractures

\begin{tabular}{|c|c|c|c|c|c|c|}
\hline $\bar{M}$ & $\mathbf{F}$ & Subtotal patients hospitalized & Age group (years) & $M$ & $\mathrm{~F}$ & Subtotal patients not hospitalized \\
\hline & 245 & 245 & 45 to 64 & & 562 & 562 \\
\hline 95 & 155 & 250 & 65 to 74 & 171 & 483 & 654 \\
\hline 108 & 206 & 314 & Older than 75 & 203 & 699 & 902 \\
\hline 203 & 606 & 809 & Total & 374 & 1,744 & 2,118 \\
\hline \multicolumn{2}{|c|}{ Patients hospitalized } & $27.6 \%$ & & \multicolumn{2}{|c|}{ Patients not hospitalized } & $72.4 \%$ \\
\hline
\end{tabular}

Number of patients hospitalized because of the fracture versus number of patients discharged directly from the Emergency Department.

Table 12 Incidence of fragility fractures per 100 inhabitants in Italy (2006)

\begin{tabular}{llll}
\hline Fractures & $\mathbf{M}$ & $\mathbf{F}$ & Total \\
\hline Hip \\
$(\mathrm{M}>65+\mathrm{F}>65)$ & 0.41 & 1.0 & 0.75 \\
$\begin{array}{l}\text { Humerus } \\
(\mathrm{M}>65+\mathrm{F}>65)\end{array}$ & 0.16 & 0.28 & 0.25 \\
$\begin{array}{l}\text { Ankle } \\
(\mathrm{M}>65+\mathrm{F}>65)\end{array}$ & 0.11 & 0.22 & 0.19 \\
$\begin{array}{l}\text { Wrist } \\
(\mathrm{M}>65+\mathrm{F}>65)\end{array}$ & 0.15 & 0.55 & 0.44 \\
$\begin{array}{l}\text { Vertebra } \\
\text { Clinical fractures } \\
(\mathrm{M}>65+\mathrm{F}>65)\end{array}$ & 0.22 & 0.25 & 0.24 \\
\hline
\end{tabular}

occurring at skeletal sites other than the hip are an underestimated issue that is difficult to analyze because they do not systematically result in hospital admissions as a consequence of the lack of specific diagnostic codes for fragility fractures. While confirming the extremely high burden of hip fractures in the Italian population [13], at the same time, this study represents the first attempt to evaluate the incidence of "minor" fragility fractures in Italy. Until now, it was possible to refer to US, UK, Australian and Swedish data concerning fragility fractures other than those occurring at the hip [31-34]. According to these studies, the lifetime risk (percentage) of developing a vertebral clinical fracture 
Table 13 Overall estimation of fragility fractures and F/M ratio in Italy (2006)

\begin{tabular}{lllll}
\hline & Total & & \multicolumn{2}{c}{ F/M Ratio in patients older than $\mathbf{6 5}$ years } \\
\cline { 3 - 5 } & & $\mathbf{6 5}$ to $\mathbf{7 4}$ years & Older than $\mathbf{7 5}$ years & Overall older than $\mathbf{6 5}$ years \\
\hline $\begin{array}{l}\text { Hip fractures } \\
(\mathrm{M}>65+\mathrm{F}>65)\end{array}$ & 87,000 & 3.48 & 3.43 \\
$\begin{array}{l}\text { Humeral fractures } \\
(\mathrm{M}>65+\mathrm{F}>45)\end{array}$ & 48,000 & 2.99 & 4.98 & 4.10 \\
$\begin{array}{l}\text { Ankle fractures } \\
(\mathrm{M}>65+\mathrm{F}>45)\end{array}$ & 36,000 & 3.15 & 3.19 & 3.17 \\
$\begin{array}{l}\text { Wrist fractures } \\
(\mathrm{M}>65+\mathrm{F}>45)\end{array}$ & 85,000 & 5.01 & 9.04 & 6.85 \\
$\begin{array}{l}\text { Vertebral fractures } \\
(\mathrm{M}>65+\mathrm{F}>45)\end{array}$ & $\begin{array}{l}\text { Clinical fractures } 47,000 \\
\text { Overall fractures } 155,000\end{array}$ & 2.01 & 3.27 & 2.64 \\
\hline
\end{tabular}

or a forearm fracture in the United States at the age of 50 years has been estimated to be $15.6 \%$ and $16 \%$ in women or $5 \%$ and $2.5 \%$ in men, respectively [31]. The corresponding figures are $15.1 \%$ and $20.8 \%$ (women) or $8.3 \%$ and $4.6 \%$ (men), respectively, for clinical vertebral fractures and forearm fractures in Sweden [32], 3.1\% and $16.6 \%$ (women) or $1.2 \%$ and $2.9 \%$ (men) in the UK [33], and 9.6\% (spine) and 13.3\% (wrist) in Australian women (no data available for men) [34]. However, it is difficult to use these rates in the evaluation of fracture incidence in the Italian population because the weight of people aged older than 65 years (ratio between elderly people and general population) is much higher in Italy than in the United States, Australia, or other European countries. These first Italian data, resulting from a 3year multicenter clinical survey, could allow us to overcome the limitations arising from the use of foreign rates and are particularly valuable because Italy represents one of the countries with the highest life expectancies in the world, thus anticipating possible demographic scenarios of other European industrialized countries. Although the main limitation of the study is that it was not possible to analyze all fragility fractures occurring in Italy (as a consequence of the lack of a specific codification for fragility fractures and because only hospitalized fractures are recorded in national databases), our sample was likely to be representative of the whole Italian population who develop osteoporotic fragility fractures, thanks to the huge number of patients enrolled $(29,017$ with fractures), their distribution across the three different selected age groups (45 to 64, 65 to 74, and older than 75 years), and taking into account that the survey involved big hospitals of different Italian regions, thus overcoming possible interregional variability.

We are concerned about potential underestimation of vertebral fractures in our analysis because we have considered all clinical fractures to be referred to the Emergency Department, whereas in daily clinical practice, patients may also ask their general practitioners for a treatment or undergo a clinical evaluation while ambulatory. Conversely, we tried to avoid possible overestimations in the number of osteoporotic fractures by excluding from the analysis all men aged 45 to 64 years, even if investigators had classified those events as fragility fractures. Our data show that the absence of ICD9-CM codes for fragility fractures results in underestimation of "minor fractures" (those occurring at skeletal sites other than the hip), causing problems in the full evaluation of the osteoporosis impact in elderly people. Moreover, the underestimation of fragility fractures is also due to an underdiagnosis of osteoporosis in patients at higher risk (particularly postmenopausal women), resulting in undertreatment of this pathology and consequently in additional increase of osteoporotic fractures. On the contrary, it is known that appropriate treatments can prevent many osteoporotic fractures occurring in a high-risk population. Our data confirm an underestimation of "minor" fragility fractures and call for specific preventive strategies based on actions (such as optimization of access to antifracture therapies and compliance with the treatments, proper dietary calcium intake during the whole life, vitamin D supplementations, physical activity programs) to be carried out at the regional level all over the nation, as stated in the conclusions of the official inquiry promoted by the Italian Senate in 2002, specifically addressing the burden of osteoporosis in Italy [35]. Our data also emphasize the need for implementing a national registry of fragility fractures, whose start-up phase has been anticipated by this multicenter survey performed at Emergency Departments. The incidence rates resulting from this study may also be useful for carrying out further studies aimed to update national data of the Italian version of the international algorithm FRAX, which has been developed to provide physicians with a specific tool for the estimation of patients' individual risk of fragility fractures (as the algorithm is mainly based on data obtained from Scandinavian and North American populations) [36]. 


\section{Conclusions}

Based on a 3-year multicenter survey, we have estimated in Italy an annual incidence of 410,000 new hip, humeral, wrist, ankle, and vertebral fragility fractures. These results confirm that osteoporosis is a leading cause of morbidity in the Italian population and a challenging health problem to be addressed by implementing appropriate preventive strategies.

\section{Abbreviations}

ESOPO: Epidemiological Study on the Prevalence of Osteoporosis in Italy; EVOS: European Vertebral Osteoporosis Study; ISTAT: Italian National Institute for Statistics; SDO: National hospitalizations database; WHO: World Health Organization.

\section{Author details}

'Division of Orthopaedics and Traumatology, Tor Vergata Foundation University Hospital, University of Rome, Tor Vergata, Viale Oxford 81, Rome, 00133, Italy. ${ }^{2}$ Department of Orthopaedics, University of Cagliari, Lungomare Poetto, Cagliari, 09124, Italy. ${ }^{3}$ Division of Orthopaedic and Traumatology, University of Palermo, Via Antonio Veneziano 120, Palermo, 90139, Italy. ${ }^{4}$ Department of Physical and Rehabilitative Medicine, University of Palermo, Via Antonio Veneziano 120, Palermo, 90139, Italy. ${ }^{5}$ Division of Orthopaedics and Traumatology I, San Giovanni Addolarata Britannico Hospital, Via dell'Amba Aradam 9, Rome, 00184, Italy. ${ }^{6}$ Division of Orthogeriatrics, San Camillo Hospital, Piazza Carlo Forlanini 1, Rome, 00151, Italy. ${ }^{7}$ Division of Orthopaedics and Traumatology, University of Bari, Piazza Giulio Cesare 11, Bari, 70124, Italy. ${ }^{8}$ Division of Orthopaedics and Traumatology II, Spedali Riuniti di Brescia, Piazzale Spedali Civili 1, Brescia, 25123, Italy. ${ }^{9}$ Division of Orthopaedics and Traumatology, Maria Vittoria Hospital, Via Cibrario 72, Turin, 10144, Italy. ${ }^{10}$ Division of Orthopaedics, University of Catania, University Hospital Vittorio Emanuele, Via S.Sofia 78, Catania, 95123, Italy. ${ }^{11}$ Department of Orthopaedics and Traumatology I, University of Milan, Orthopedic Institute G.Pini, Piazza Cardinale Ferrari 1, Milan, 20100, Italy. ${ }^{12}$ Department of Orthopaedics and Rehabilitative Medicine, Second University of Naples, Via Luigi De Crecchio, Naples, 80138, Italy.

${ }^{13}$ Department of Internal Medicine, University of Florence, Viale Pieraccini 18 50134 Florence, Italy

\section{Authors' contributions}

UT, AC, MP, MDA, GLM, Al, AF, FP, VP, AS, UEP, GZ, MR, GM, GS, MP, CAV, and $C C$ conceived of the study, participated in its design, and assisted in the enrollment of all the patients in the study at each clinical center. UT coordinated the study. UT, PP, MF, AP, LS, AS, CR Gl, and MLB performed all the descriptive and statistical analyses of the study and designed the outline of the article. All the authors contributed to drafting the manuscript.

\section{Competing interests}

UT, AC, MP, MDA, GLM, Al, AF, FP, VP, AS, UEP, GZ, MR, GM, GS, MP, CAV, CC, $\mathrm{Gl}$, and MLB have received research grants and funding for consulting/ speaking from Merck, Chiesi, Sanofi-Aventis, Novartis, Stroder, Servier, Ely Lilly, Roche, and Nicomed; PP has received funding for consulting/speaking from Novartis, AMGEN, and Sanofi-Aventis; MF, AP, LS, AS, and CR have no disclosures.

Received: 22 August 2010 Revised: 10 December 2010 Accepted: 29 December 2010 Published: 29 December 2010

\section{References}

1. National Institute for Statistics: Italian Statistics 2005 Rome: National Institute for Statistics; 2005.

2. World Health Organization. WHO statistical information system (WHOSIS). [http://apps.who.int/ghodata/?vid=720].

3. Kanis JA, Burlet N, Cooper C, Delmas PD, Reginster JY, Borgstrom F, Rizzoli R: European Society for clinical and economic (aspects of osteoporosis and osteoarthritis ESCEO): European guidance for the diagnosis and management of osteoporosis in postmenopausal women. Osteoporos Int 2008, 19:399-428.
4. Piscitelli P, Guida G, Iolascon G, Muratore M, Camboa P, Borgia O, Forcina B, Fitto F, Robaud V, Termini G, Rini GB, Gianicolo E, Faino A, Rossini M, Adami S, Angeli A, Distante A, Gatto S, Gimigliano R, Guida G: SIOMMMS study group: CERSUM research group: incidence and costs of hip fractures vs. acute myocardial infarction in the Italian population: a 4 years survey. Osteoporos Int 2007, 18:211-219.

5. Adami S, Giannini S, Giorgino R, Isaia G, Maggi S, Sinigaglia L, Filipponi P, Crepaldi G, Di Munno O: The effect of age, weight, and lifestyle factors on calcaneal quantitative ultrasound: the ESOPO study. Osteoporos Int 2003, 14:198-207.

6. Siris ES, Brenneman SK, Barrett-Connor E, Miller PD, Sajjan S, Berger ML, Chen YT: The effect of age and bone mineral density on the absolute, excess, and relative risk of fracture in postmenopausal women aged 5099: results from the National Osteoporosis Risk Assessment (NORA). Osteoporos Int 2006, 17:565-574.

7. Krieg MA, Cornuz J, Ruffieux C, Van Melle G, Büche D, Dambacher MA Hans D, Hartl F, Häuselmann HJ, Kraenzlin M, Lippuner K, Neff M, Pancaldi P, Rizzoli R, Tanzi F, Theiler R, Tyndall A, Wimpfheimer C, Burckhardt P: Prediction of hip fracture risk by quantitative ultrasound in more than 7000 Swiss women $>$ or $=70$ years of age: comparison of three technologically different bone ultrasound devices in the SEMOF study. J Bone Miner Res 2006, 21:1457-1463.

8. Maggi S, Noale M, Giannini S, Adami S, Defeo D, Isaia G, Sinigaglia L, Filipponi P, Crepaldi G, ESOPO Study Group: Quantitative heel ultrasound in a population-based study in Italy and its relationship with fracture history: the ESOPO study. Osteoporos Int 2006, 17:237-244.

9. Riggs BL, Melton L: The worldwide problem of osteoporosis: insights afforded by epidemiology. Bone 1995, 17:505S-511S.

10. Iolascon G, Guida G, Piscitelli P, Guida G: Hip fractures in Italy, analysis of DRG data. Aging Clin Exp Res 2007, 19:2-4.

11. Piscitelli P, Camboa P, Fitto F, Iolascon G, Guida G: Femoral fractures and orthopaedic surgery: a 4-year survey in Italy. J Orthopaed Traumatol 2005, 6:203-206.

12. Piscitelli P, lolascon G, Gimigliano F, Muratore M, Camboa P, Borgia O, Forcina B, Fitto F, Robaud V, Termini G, Rini GB, Gianicolo E, Faino A, Rossini M, Adami S, Angeli A, Distante A, Gatto S, Gimigliano R, Guida G, SIOMMMS study group, CERSUM research group: CERSUM research group: incidence and costs of hip fractures vs. acute myocardial infarction in the Italian population: a 4 years survey. Osteoporos Int 2007, 18:211-219.

13. Piscitelli $P$, Gimigliano F, Gatto $S$, Marinelli A, Gimigliano A, Marinelli $P$, Chitano G, Greco M, Di Paola L, Sbenaglia E, Benvenuto M, Muratore M, Quarta E, Calcagnile F, Coli G, Borgia O, Forcina B, Fitto F, Giordano A, Distante A, Rossini M, Angeli A, Migliore A, Guglielmi G, Guida G, Brandi ML, Gimigliano R, Iolascon G: Hip fractures in Italy: 2000-2005 extension study. Osteoporos Int 2010, 21:1323-1330.

14. Cummings SR, Melton L: Epidemiology and outcomes of osteoporotic fractures. Lancet 2002, 359:1761-1767.

15. O'Neill TW, Felsenberg D, Varlow J, Cooper C, Kanis JA, Silman AJ: The prevalence of vertebral deformity in European men and women: the European Vertebral Osteoporosis Study. J Bone Miner Res 1996, 11:1010-1018.

16. Ettinger B, Black DM, Nevitt MC, Rundle AC, Cauley JA, Cummings SR, Genant HK: Contribution of vertebral deformities to chronic back pain and disability: the study of Osteoporotic Fractures Research Group. J Bone Miner Res 1992, 7:449-456.

17. Nevitt MC, Ettinger B, Black DM, Stone K, Jamal SA, Ensrud K, Segal M, Genant HK, Cummings SR: The association of radiographically detected vertebral fractures with back pain and function: a prospective study. Ann Intern Med 1998, 128:793-800.

18. Hasserius R, Karlsson MK, Nilsson BE, Redlund-Johnell I, Johnell O: European Vertebral Osteoporosis Study: prevalent vertebral deformities predict increased mortality and increased fracture rate in both men and women: a 10-year population-based study of 598 individuals from the Swedish cohort in the European Vertebral Osteoporosis Study. Osteoporos Int 2003, 14:61-68.

19. Lindsay R, Silverman SL, Cooper C, Hanley DA, Barton I, Broy SB, Licata A, Benhamou L, Geusens P, Flowers K, Stracke H, Seeman E: Risk of new vertebral fracture in the year following a fracture. JAMA 2001, 285:320-323.

20. Pongchaiyakul C, Nguyen ND, Jones G, Center JR, Eisman JA, Nguyen TV: Asymptomatic vertebral deformity as a major risk factor for subsequent 
fractures and mortality: a long-term prospective study. I Bone Miner Res 2005, 20:1349-1355.

21. Ismail AA, O'Neill TW, Cooper C, Finn JD, Bhalla AK, Cannata JB, Delmas P, Falch JA, Felsch B, Hoszowski K, Johnell O, Diaz-Lopez JB, Lopez Vaz A, Marchand F, Raspe H, Reid DM, Todd C, Weber K, Woolf A, Reeve J, Silman AJ: Mortality associated with vertebral deformity in men and women: results from the European Prospective Osteoporosis Study (EPOS). Osteoporos Int 1998, 8:291-297.

22. Fechtenbaum J, Cropet C, Kolta S, Verdoncq B, Orcel P, Roux C: Reporting of vertebral fractures on spine X-rays. Osteoporos Int 2005, 16:1823-1826.

23. Cummings SR, Melton L: Epidemiology and outcomes of osteoporotic fractures. Lancet 2002, 359:1761-1767.

24. Klotzbuecher CM, Ross PD, Landsman PB, Abbott TA, Berger M: Patients with prior fractures have an increased risk of future fractures: a summary of the literature and statistical synthesis. J Bone Miner Res 2000, 15:721-739.

25. Clinton J: Proximal humeral fracture as a risk factor for subsequent hip fractures. J Bone Joint Surg (Am) 2009, 91:503-511.

26. Kelsey JL, Browner WS, Seeley DG, Nevitt MC, Cummings SR: Risk factors for fractures of the distal forearm and proximal humerus. Am J Epidemiol 1992, 135:477-489

27. Nevitt MC, Ettinger B, Black DM, Stone K, Jamal SA, Ensrud K, Segal M, Genant HK, Cummings SR: The association of radiographically detected vertebral fractures with back pain and function: a prospective study. Ann Intern Med 1998, 128:793-800

28. Cooper C, Atkinson EJ, O'Fallon WM, Melton L: Incidence of clinically diagnosed vertebral fractures: a population-based study in Rochester, Minnesota, 1985-1989. J Bone Miner Res 1992, 7:221-227.

29. Fink HA, Milavetz DL, Palermo L, Nevitt MC, Cauley JA, Genant HK, Black DM, Ensrud KE: Fracture Intervention Trial Research Group: What proportion of incident radiographic vertebral deformities is clinically diagnosed and vice versa? J Bone Miner Res 2005, 20:1216-1222.

30. Ettinger B, Black DM, Mitlak BH, Knickerbocker RK, Nickelsen T, Genant HK, Christiansen C, Delmas PD, Zanchetta JR, Stakkestad J, Glüer CC, Krueger K, Cohen FJ, Eckert S, Ensrud KE, Avioli LV, Lips P, Cummings SR: Reduction of vertebral fracture risk in postmenopausal women with osteoporosis treated with raloxifene: results froma 3-year randomized clinical trial: multiple outcomes of raloxifene evaluation (MORE) investigators. JAMA 1999, 282:637-645

31. Melton $L \mathrm{III}$, Chriscilles EA, Cooper C, Lane AW, Riggs BL: Perspective: How many women have osteoporosis? J Bone Miner Res 1992, 7:1005-1010.

32. Kanis JA, Johnell O, Oden A, Sernbo I, Redlund-Johnell I, Dawson A, de Laet C, Jönsson B: Long-term risk of osteoporotic fracture in Malmö. Osteoporos Int 2000, 11:669-674.

33. van Staa TP, Dennison EM, Leufkens HG, Cooper C: Epidemiology of fractures in England and Wales. Bone 2001, 29:517-522.

34. Doherty DA, Sanders KM, Kotowicz MA, Prince RL: Lifetime and five-year age-specific risks of first and subsequent osteoporotic fractures. 2001. Osteoporos Int 2001, 12:16-23.

35. Italian Senate Health Commission (eds): Official Report of the Survey on Osteoporosis Rome; Italian Senate; 2002.

36. Ettinger B, Black DM, Dawson-Hughes B, Pressman AR, Melton LJ III: Updated fracture incidence rates for the US version of FRAX. Osteoporos Int 2010, 21:25-33.

doi:10.1186/ar3213

Cite this article as: Tarantino et al.: The incidence of hip, forearm,

humeral, ankle, and vertebral fragility fractures in Italy: results from a 3year multicenter study. Arthritis Research \& Therapy 2010 12:R226.

\section{Submit your next manuscript to BioMed Central and take full advantage of:}

- Convenient online submission

- Thorough peer review

- No space constraints or color figure charges

- Immediate publication on acceptance

- Inclusion in PubMed, CAS, Scopus and Google Scholar

- Research which is freely available for redistribution

Submit your manuscript at www.biomedcentral.com/submit
Biomed Central 